\title{
Optimisation of multi-point forming process parameters
}

\author{
Mohamed Abosaf $^{1} \cdot$ Khamis Essa $^{1} \cdot$ Ali Alghawail $^{1} \cdot$ Abror Tolipov $^{1} \cdot$ Shizhong Su$^{1} \cdot$ \\ Duc Pham ${ }^{1}$
}

Received: 27 October 2016 / Accepted: 9 February 2017 / Published online: 22 March 2017

(C) The Author(s) 2017. This article is published with open access at Springerlink.com

\begin{abstract}
The need for sheet metal forming using reconfigurable dies has increased due to rapid changes in part design to meet customer requirements, especially in the automotive industry. Reconfigurable dies have relatively low manufacturing cost compared with solid dies, and the same tool can be readily changed to produce different parts. Previous investigations have focused on avoiding defects without taking into account the effects of process on the quality characteristics of fabricated parts. This study investigated the influence of parameters, such as the elastic cushion thickness, coefficient of friction, pin size and radius of curvature, on the quality of parts formed in a flexible multi-point stamping die. The aim was to determine the optimum values of those parameters. Finite element modelling was employed to simulate the multi-point forming of hemispherical parts. Using the response surface method, the effects of process parameters on wrinkling, deviation from the target shape and thickness variation were investigated and the process parameters yielding the best product quality characteristics were obtained. The results show that pin size and radius of curvature have the greatest influence on wrinkling and deviation between formed and target shapes, while coefficient of friction, pin size and radius of curvature significantly affect thickness variation.
\end{abstract}

Keywords Multi-point forming - Reconfigurable press tool · Sheet metal forming $\cdot$ Finite element analysis $\cdot$ Design of experiment

Khamis Essa

k.e.a.essa@bham.ac.uk

School of Mechanical Engineering, University of Birmingham, Edgbaston, Birmingham B15 2TT, UK

$\begin{array}{ll}\text { Nomencalture } \\ \text { MPF } & \text { Multi-point forming } \\ \text { DOE } & \text { Design of experiment } \\ \text { ANOVA } & \text { Analysis of variance } \\ \sigma & \text { True stress } \\ k & \text { Strength coefficient } \\ n & \text { Strain hardening } \\ \varepsilon & \text { True strain } \\ \nu & \text { Poisson ratio } \\ \rho & \text { Density } \\ W & \text { Strain energy per unit volume } \\ C_{01}, C_{10} & \text { Temperature-dependent material properties } \\ I_{1}, I_{2} & \text { First and second invariants of the deviatoric } \\ \text { RMSE } & \text { Root-mean-square error } \\ n & \text { Number of wrinkling waves } \\ z & \text { Maximum amplitude of wrinkling wave } \\ \text { SD } & \text { Standard deviation } \\ N & \text { Number of data points } \\ x_{i} & \text { Value in the data set } \\ \bar{x} & \text { Mean of the data set } \\ q & \text { Response } \\ k_{0}-k_{14} & \text { Process parameter coefficients } \\ A & \text { Elastic cushion thickness } \\ B & \text { Coefficient of friction } \\ C & \text { Pin size } \\ D & \text { Radius of curvature }\end{array}$

\section{Introduction}

Sheet metal forming using multi-point pin stamping is a useful technique for producing three-dimensional parts. A multi-point forming (MPF) die uses a matrix of pins, which can move normally to the die base to create the die surface. The process is flexible to accommodate rapid changes in product design without 
affecting tooling costs. Many investigations have been conducted to develop the MPF technique [1-4]. Walczyk and Hardt [1] reviewed MPF die design techniques, which include construction of the die model, clamping of the pin matrix, containment frame and load capacity. Qian et al. [2] reported that complex shapes such as satellite heads can be fabricated using MPF. Cia et al. [3] investigated the effect of the contact points between the pins and sheet on process defects, such as dimpling, wrinkling and spring back. The effect of forming force and mesh size on these defects was also investigated. For a given pin setup, a large number of numerical simulations are required to obtain the design shape without defects. Paunoiu et al. [4] investigated the impact of the pin network type on the deformation process in MPF with a fixed configuration. Sheet thickness, stress, forming force and spring back were used as measures to evaluate the process. They found that the pin type selected depends on the design reasons. Paunoiu et al. [5] developed numerical simulation models using a dynamic finite element programme and investigated the effect of tool geometry as well as the use of an elastic cushion on the deformation behaviours. The elastic cushion had a positive effect on the part surface and a negative effect on shape accuracy. Kareem and Imad [6] investigated the effect of localised deformation on surface quality and the important role of the elastic cushion in preventing the formation of dimples. It was found that a thicker elastic cushion leads to geometrical errors in the fabricated part. Liu et al. [7] studied the impact of cushion material, cushion thickness and coefficient of friction on surface quality in micro multipoint sheet forming and found that proper selection of elastic cushion material and thickness can significantly improve surface quality, especially when combined with using lubrication. Abebe et al. [8] proposed surrogate-based multi-objective optimisation to reduce wrinkling and dimpling during the MPF process. However, they did not consider uncertainties in factors such as material properties, friction at the interfaces and the workpiece thickness, which may deteriorate the quality of the workpiece during multi-point dieless forming. However, the study ignored the influence of pin dimensions.
Previous investigations have focused on qualitatively studying the effects of pin configuration, elastic cushion material/ thickness and coefficient of friction on the formation of defects and surface quality. An investigation that covers a range of process parameters and their effects on quality characteristics (i.e. surface quality and geometrical accuracy) is required to provide a better understanding of the process. Statistical analysis by means of design of experiments (DOEs) and analysis of variance (ANOVA) is widely used in manufacturing to investigate the influence of process parameters [9, 10].

In this work, the response surface method and finite element modelling were employed to determine the most important process parameters in MPF. The influence of process parameters including elastic cushion thickness, coefficient of friction, pin size and radius of curvature on the quality characteristics of formed parts was evaluated. The quality characteristics of interest included surface quality measures such as wrinkling and geometrical accuracy measures such as maximum deviation from target shape and thickness uniformity. Additionally, the optimum process parameters to minimise thickness variation and deviation from target shape without formation of wrinkles were obtained.

The remainder of the paper is structured as follows. Section 2 gives details of the finite element model and the properties of materials used. Section 3 describes the DOEs to investigate the effects of process parameters on response parameters. To validate the model, Sect. 4 compares the modelling against previous experimental work. Section 5 discusses the modelling results obtained. Section 6 describes the use of the model to predict the response parameters. Section 7 discusses the optimal forming of a spherically shaped component. Section 8 concludes the paper.

\section{Numerical modelling of multi-point forming}

FE models were developed for a MPF die, which consists of a pair of pin matrices, a blank sheet and two elastic cushions.
Fig. 1 Three pin matrix configurations. a $10 \times 10$ matrix with 10 -mm pin tip radius. b $6 \times 6$ matrix with $15-\mathrm{mm}$ pin tip radius. c $5 \times 5$ matrix with 20 -mm pin tip radius

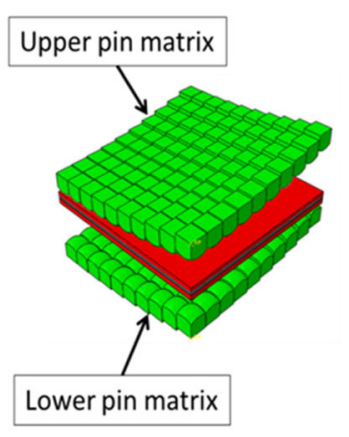

(a) 10x10 matrix with $10 \mathrm{~mm}$ pin tip radius

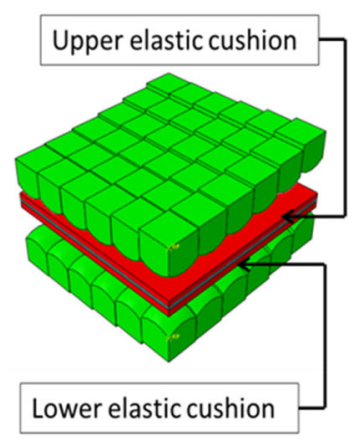

(b) $6 \times 6$ matrix with $15 \mathrm{~mm}$ pin tip radius

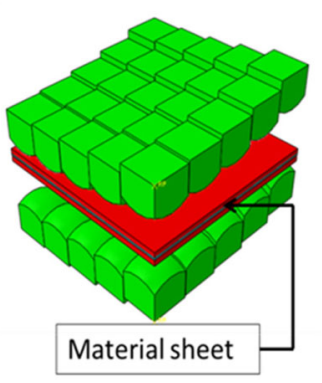

(c) $5 \times 5$ matrix with $20 \mathrm{~mm}$ pin tip radius 


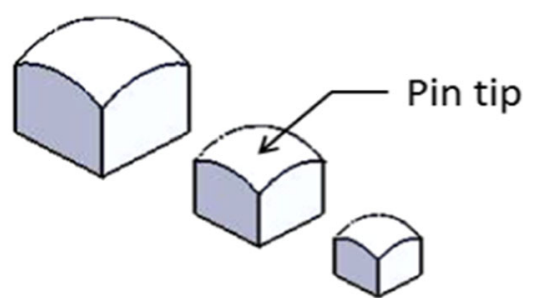

R20
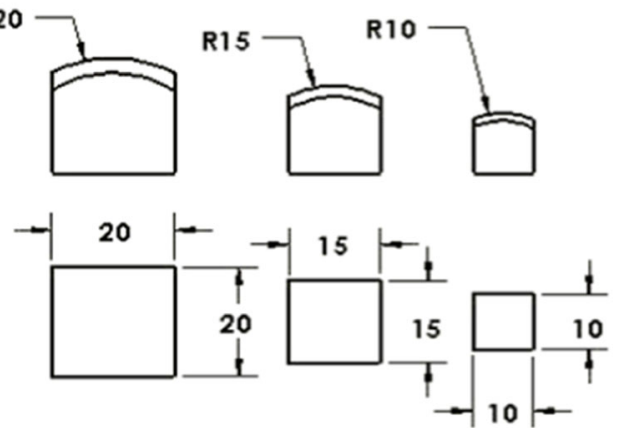

Fig. 2 The pin shapes and dimensions for the three pin configurations (all dimensions in $\mathrm{mm}$ )

Due to symmetry, only a quarter of the die was simulated to reduce computation time. The pins have a hemispherical tip and square cross section. Three pin tip radii were considered, namely, 10, 15 and $20 \mathrm{~mm}$. The length of the square cross section is equal to the tip radius. Three pin configurations were simulated: a $10 \times 10$ matrix (using a $10-\mathrm{mm}$ pin tip radius), a $6 \times 6$ matrix (using a $15-\mathrm{mm}$ pin tip radius) and a $5 \times 5$ matrix (using a 20-mm pin tip radius) as shown in Fig. 1a-c. Figure 2 shows the pin shapes and dimensions.

The material of the blank sheet used in the numerical simulation is medium-strength DC05 steel with 1-mm thickness. The mechanical properties of DC05 steel are shown in Table 1. The material was assumed to be isotropic, and the elasto-plastic model was used. Power law equation was selected to represent the flow stress of the material as shown in Eq. 1 [11].

$\sigma=k \cdot \varepsilon^{n}$

where $\sigma$ is the true stress, $k$ is the strength coefficient, $\varepsilon$ is the true strain, and $n$ is the strain hardening.

Figure 3 shows the stress-strain curve of DC05 sheet steel obtained from a uniaxial tensile test using a Zwick tensile test

Table 1 Mechanical properties of the sheet metal

\begin{tabular}{ll}
\hline Properties & Values \\
\hline Modulus of elasticity $(E)$ & $220 \mathrm{GPa}$ \\
Yield stress $\left(\sigma_{o}\right)$ & $201.9 \mathrm{MPa}$ \\
Poisson ratio $(\nu)$ & 0.3 \\
Density $(\rho)$ & $7870 \mathrm{~kg} / \mathrm{m}^{3}$ \\
Strength coefficient $(k)$ & $527.13 \mathrm{MPa}$ \\
Strain-hardening exponent $(n)$ & 0.17 \\
\hline
\end{tabular}

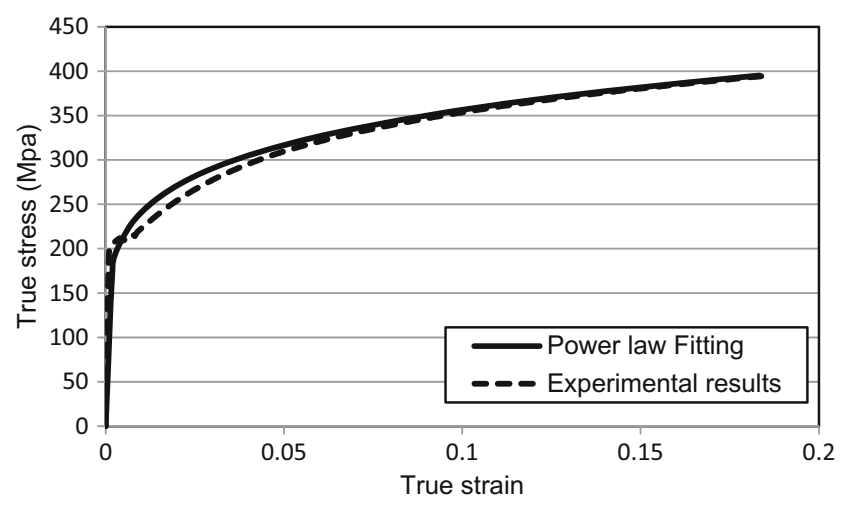

Fig. 3 Stress-strain curve for DC05 steel compared with theoretical model

machine and the curve generated by fitting a power law to the experimental data.

An elastic cushion is required in MPF to protect the sheet from dimpling $[12,13]$. In this investigation, the material of the elastic cushion was chosen to be polyurethane A-90 as it is commonly used in this process [13]. Figure 4 shows the flow stress for polyurethane A-90 obtained using a Zwick tensile test machine. The experimental results are very similar to those by Seo et al. [14]. The experimental behaviour of the elastic cushion was also compared against three material models, namely Mooney-Rivlin, Neo-Hooke and Yeoh. As shown in Fig. 4, the hyperelastic model (Mooney-Rivlin model) describes well the hyperelastic behaviour of polyurethane A-90. The model can be expressed using the following equation:

$W=C_{10}\left(I_{1}-3\right)+C_{01}\left(I_{2}-3\right)$

where $W$ is the strain energy per unit volume, $I_{1}$ and $I_{2}$ are the first and second invariants of the deviatoric strain tensor, and $C_{10}$ and $C_{01}$ are the temperature-dependent material properties obtained from a uniaxial compression test conducted using a Shore hardness of 90 . The values of $C_{10}$ and $C_{01}$ are 0.861 and 0.354 , respectively.

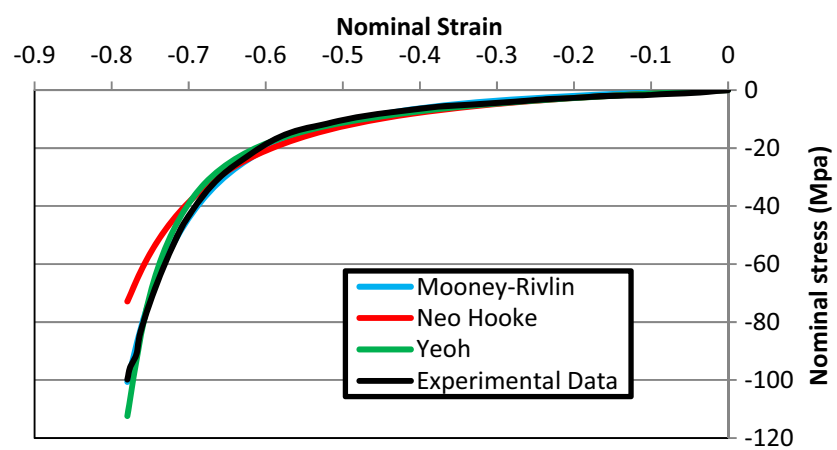

Fig. 4 Nominal compression stress-strain relationship for polyurethane A-90 compared with Mooney-Rivlin, Neo-Hooke and Yeoh models 
Fig. 5 Element mesh type and boundary conditions

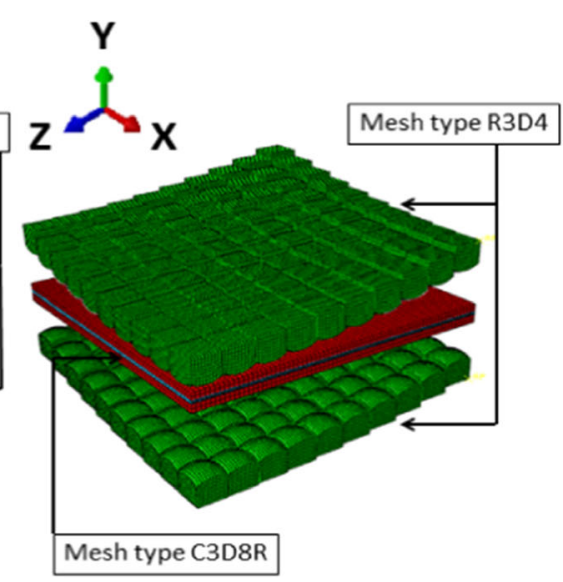

The metal sheet and elastic cushion were modelled as deformable bodies, and the ABAQUS C3D8R quadratic element type was used [15]. The numbers of elements for the metal sheet and the 3-mm-thick elastic cushion were 288,300 and 9248, respectively. The upper and lower dies were modelled as rigid bodies, and the element type was R3D4. The number of elements for the upper die was equal to that for the lower die in all three models 59,400; 46,080; and 53,550 elements for dies with pin sizes 10, 15 and $20 \mathrm{~mm}$, respectively. Since only a quarter of the model was considered, symmetric boundary conditions were applied to the sheet and elastic cushion. Displacement boundary conditions were used to fix the lower die in the $\mathrm{X}, \mathrm{Y}$ and $\mathrm{Z}$ directions and the upper die in the $\mathrm{X}$ and $\mathrm{Z}$ directions. The upper die was moved in the $\mathrm{Y}$ direction. The finite element mesh and boundary conditions are shown in Fig. 5.

In common with simulations of other sheet metal forming processes such as conventional deep drawing and stamping, an explicit solver was used to avoid convergence issues because the number of elements was high, and the contact problem was complicated $[8,16]$.

\section{Model validation}

The finite element model was validated against experimentally published results obtained by Kadhim et al. [17]. As shown in Fig. 6, the force gradually increased

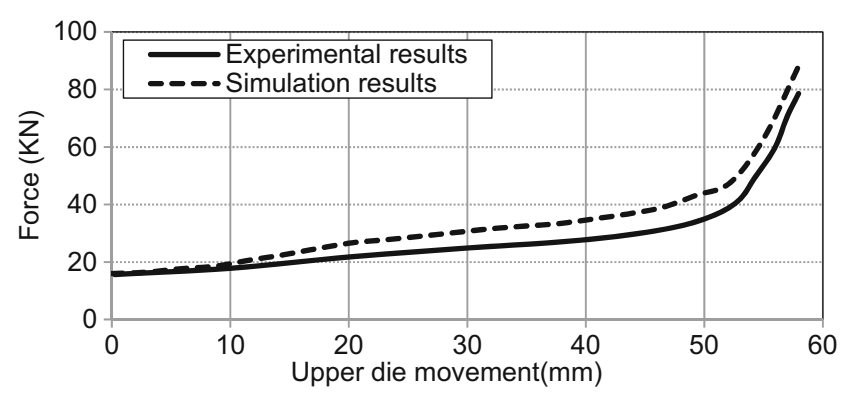

Fig. 6 Comparison of predicted and experimental forces to $45 \mathrm{kN}$, which corresponds to $50 \mathrm{~mm}$ of the upper die displacement. At this position, all pins were in contact with the elastic cushion and plastic deformation started to take place. After that, the force rapidly increased with plastic deformation due to strain hardening of the material. The maximum predicted force is about $88 \mathrm{kN}$ when the upper and lower dies are closed. The predicted forming force was compared to the measured force, as shown in Fig. 8, and good agreement was found with a maximum error of about $11 \%$.

\section{Design of experiments}

The objectives of experiment design are to show the effect of process parameters on response parameters and to determine the most critical forming parameters affecting each response parameter. This then enables the identification of parameters giving the best response. The pin size, thickness of the elastic cushion, radius of curvature and coefficient of friction were selected as the main process parameters as in previous investigations [7, 14]. Wrinkling, maximum deviation between formed shape and target shape and thickness variation were used to represent the quality of the formed part. The central composite response surface method was used to generate a set of experiments for four process parameters in which each factor was varied over three levels: low, intermediate and high. Table 2 shows the

Table 2 Process parameters

\begin{tabular}{lllll}
\hline \multirow{2}{*}{ Parameters } & \multirow{2}{*}{ Unit } & \multicolumn{2}{l}{ Levels } & \\
\cline { 3 - 5 } & & Low & Intermediate & High \\
\hline Elastic cushion thickness $(A)$ & $\mathrm{mm}$ & 3 & 6 & 9 \\
Coefficient of friction $(B)$ & - & 0 & 0.05 & 0.1 \\
Pin size $(C)$ & $\mathrm{mm}$ & 10 & 15 & 20 \\
Radius of curvature $(D)$ & $\mathrm{mm}$ & 400 & 600 & 800 \\
\hline
\end{tabular}


Fig. 7 Calculation of wrinkling (see also Eq. 3)

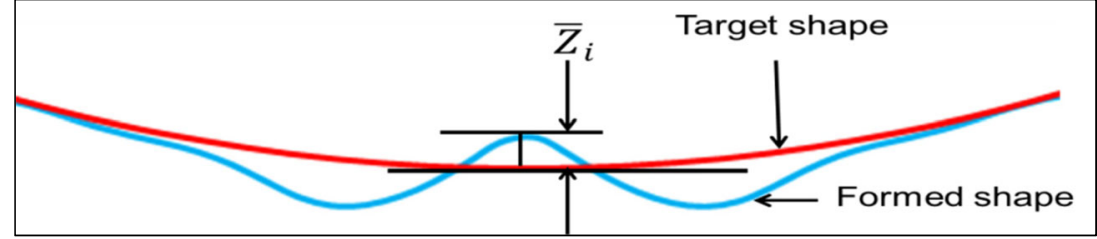

process parameters used in the simulation. Wrinkling was taken as the normal distance between the target and deformed shapes at every wrinkling amplitude as shown in Fig. 7, and the root-mean-square error (RMSE) (Eq. 3) was used to calculate the numerical value of wrinkling, where $n$ is the number of wrinkling waves and $Z_{i}$ is the amplitude of wrinkling wave. Thickness was measured at different locations across the sheet, and the standard deviation (SD), expressed in Eq. 4, was used to represent thickness variation. In Eq. $4, x_{i}$ is a value in the data set, $\bar{x}$ is the mean of the data set, and $N$ is the number of data points. The maximum deviation from the target shape, which typically occurs at the centre of the sheet, was also measured as shown in Fig. 8.

$$
\begin{aligned}
& \mathrm{RMSE}=\sqrt{\frac{1}{n} \sum_{i=1}^{n} Z_{i}^{2}} \\
& \mathrm{SD}=\sqrt{\frac{1}{N} \sum_{I=1}^{N}\left(x_{i}-\bar{x}\right)^{2}}
\end{aligned}
$$

\section{Results and discussion}

Table 3 shows the experimental plan, based on the response surface method, and the numerical results for wrinkling, thickness variation and deviation between

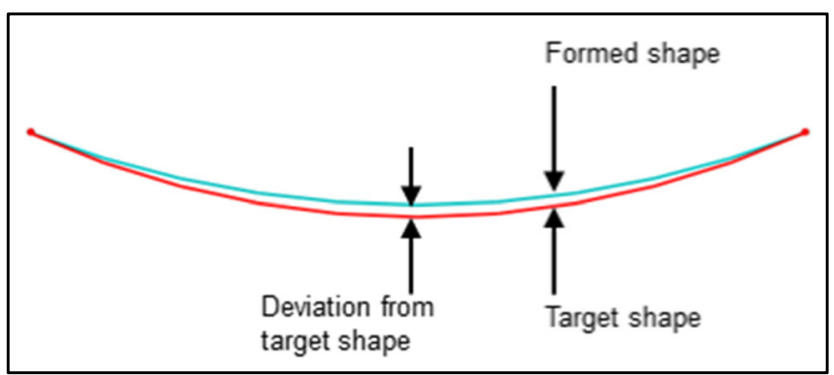

Fig. 8 Measure of maximum deviation from the target shape formed and target shapes for 27 experiments. All the simulation results were statistically analysed using Design Expert 7.0 [18, 19]. Analysis of variance (ANOVA) was performed to identify significant process parameters. In this investigation, the null hypothesis was that the factor under consideration was insignificant. A significance level of $5 \%$ was used, which means that the more the $P$ value falls below 5\%, the more important is the factor [20]. Table 4 shows the $P$ value for the main factors and interactions. The ANOVA results suggest that a quadratic model closely describes the wrinkling and maximum shape deviation while a two-factor interaction model provides a very good prediction of the thickness variation. The $R^{2}$ and adjusted $R^{2}$ values, which are measures of model best fit, did not go below $95 \%$ for any responses.

The ANOVA results in Table 4 indicate that pin size and radius of curvature are the most important factors and have a significant effect on wrinkling, maximum shape deviation and thickness variation. Friction has a significant effect on thickness variation only while cushion thickness has no important effect. Additionally, interactions between cushion thickness and friction and between cushion thickness and pin size affect thickness variation.

\subsection{Wrinkling}

Figure 9 shows the effect of pin size and radius of curvature on wrinkling. It can be seen from the surface plot that wrinkling increased noticeably with a decrease in the radius of curvature. Figure 10 reveals the stress distribution on both sides of the sheet when a small radius of curvature is used. A small radius of curvature will lead to large bending deformation, combined with plane stress as the sheet surface tries to contract under the pins. This leads to stress instability and wrinkling [3]. Small pins (less than $12.5 \mathrm{~mm}$ ) or large pins (more than $17.5 \mathrm{~mm}$ ) will increase wrinkling. Using pins that are too small will reduce the pin offset (the height difference between two adjacent pins), which forces the elastic cushion to flow towards the sheet edges. As such, the thickness of the elastic cushion at the edges increases, which leads to wrinkling. Too large a pin size will increase the pin offset causing non-uniform stress distribution especially 
Table 3 The actual design and response simulation results

\begin{tabular}{|c|c|c|c|c|c|c|c|c|}
\hline Std & Run & $\begin{array}{l}\text { Factor } 1 \\
\text { Cushion } \\
\text { thickness }\end{array}$ & $\begin{array}{l}\text { Factor } 2 \\
\text { Friction }\end{array}$ & $\begin{array}{l}\text { Factor } 3 \\
\text { Pin size }\end{array}$ & $\begin{array}{l}\text { Factor } 4 \\
\text { Radius } \\
\text { of curvature }\end{array}$ & $\begin{array}{l}\text { Response } 1 \\
\text { Wrinkling }\end{array}$ & $\begin{array}{l}\text { Response } 2 \\
\text { Max. shape } \\
\text { deviation }\end{array}$ & $\begin{array}{l}\text { Response } 3 \\
\text { Thickness } \\
\text { variation }\end{array}$ \\
\hline 7 & 1 & 3 & 0.1 & 20 & 400 & 1.62 & 2.52 & 0.002028 \\
\hline 19 & 2 & 6 & 0 & 15 & 600 & 0 & 0.74 & 0.000677 \\
\hline 13 & 3 & 3 & 0 & 20 & 800 & 0 & 0.52 & 0.000427 \\
\hline 2 & 4 & 9 & 0 & 10 & 400 & 1.64 & 2.19 & 0.001187 \\
\hline 3 & 5 & 3 & 0.1 & 10 & 400 & 1.27 & 1.84 & 0.001847 \\
\hline 6 & 6 & 9 & 0 & 20 & 400 & 1.79 & 2.5 & 0.000935 \\
\hline 11 & 7 & 3 & 0.1 & 10 & 800 & 0 & 0.37 & 0.000571 \\
\hline 1 & 8 & 3 & 0 & 10 & 400 & 1.46 & 2.19 & 0.001781 \\
\hline 24 & 9 & 6 & 0.05 & 15 & 800 & 0 & 0.33 & 0.00042 \\
\hline 9 & 10 & 3 & 0 & 10 & 800 & 0 & 0.3 & 0.000543 \\
\hline 12 & 11 & 9 & 0.1 & 10 & 800 & 0 & 0.46 & 0.001631 \\
\hline 10 & 12 & 9 & 0 & 10 & 800 & 0 & 0.62 & 0.000659 \\
\hline 16 & 13 & 9 & 0.1 & 20 & 800 & 0 & 0.74 & 0.00065 \\
\hline 17 & 14 & 3 & 0.05 & 15 & 600 & 0 & 0.68 & 0.000682 \\
\hline 22 & 15 & 6 & 0.05 & 20 & 600 & 0.749 & 1.06 & 0.000734 \\
\hline 8 & 16 & 9 & 0.1 & 20 & 400 & 1.75 & 2.48 & 0.001948 \\
\hline 23 & 17 & 6 & 0.05 & 15 & 400 & 1.1 & 1.48 & 0.001197 \\
\hline 18 & 18 & 9 & 0.05 & 15 & 600 & 0 & 0.77 & 0.000793 \\
\hline 20 & 19 & 6 & 0.1 & 15 & 600 & 0 & 0.68 & 0.001175 \\
\hline 27 & 20 & 6 & 0.05 & 15 & 600 & 0 & 0.66 & 0.000838 \\
\hline 4 & 21 & 9 & 0.1 & 10 & 400 & 1.6 & 2.02 & 0.004672 \\
\hline 26 & 22 & 6 & 0.05 & 15 & 600 & 0 & 0.66 & 0.000838 \\
\hline 14 & 23 & 9 & 0 & 20 & 800 & 0 & 0.78 & 0.000424 \\
\hline 15 & 24 & 3 & 0.1 & 20 & 800 & 0 & 0.55 & 0.000459 \\
\hline 25 & 25 & 6 & 0.05 & 15 & 600 & 0 & 0.66 & 0.000838 \\
\hline 5 & 26 & 3 & 0 & 20 & 400 & 1.69 & 2.66 & 0.001879 \\
\hline 21 & 27 & 6 & 0.05 & 10 & 600 & 0 & 1.09 & 0.001146 \\
\hline
\end{tabular}

at the edges of the sheet (where wrinkling takes place). Minimal wrinkling can be obtained when using a large radius of curvature $(800 \mathrm{~mm})$ and medium-size pins $(15 \mathrm{~mm})$.

Table 4 Process factors and corresponding $P$ values

\begin{tabular}{llll}
\hline Significant factors & \multicolumn{2}{l}{ Response factors } \\
\cline { 2 - 4 } & Wrinkling & $\begin{array}{l}\text { Max. shape } \\
\text { deviation }\end{array}$ & $\begin{array}{l}\text { Thickness } \\
\text { variation }\end{array}$ \\
\hline Cushion thickness $(A)$ & 0.2999 & 0.1691 & 0.2193 \\
Friction $(B)$ & 0.6276 & 0.2110 & 0.0071 \\
Pin size $(C)$ & 0.0344 & 0.0010 & 0.0454 \\
Radius of curvature $(D)$ & $<0.0001$ & $<0.0001$ & $<0.0001$ \\
Significant interaction & - & - & $A B=0.0145$ \\
& & & $A C=0.0476$ \\
\hline
\end{tabular}

\subsection{Maximum shape deviation}

Figure 11 shows the effect of pin size and radius of curvature on the maximum shape deviation. It can be seen from the surface plot that the maximum deviation

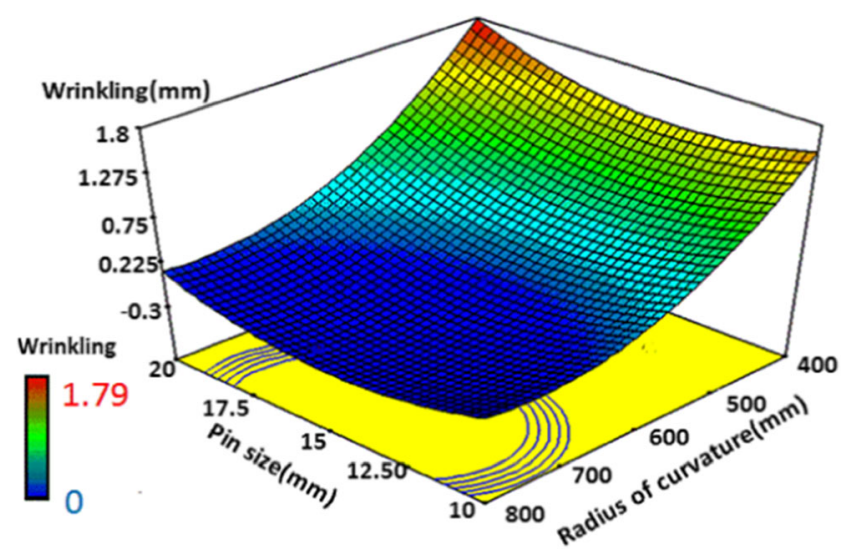

Fig. 9 Effect of pin size and radius of curvature on wrinkling 
Fig. 10 Pressure distribution on upper and lower sides of sheet (radius of curvature $=400 \mathrm{~mm}$ )
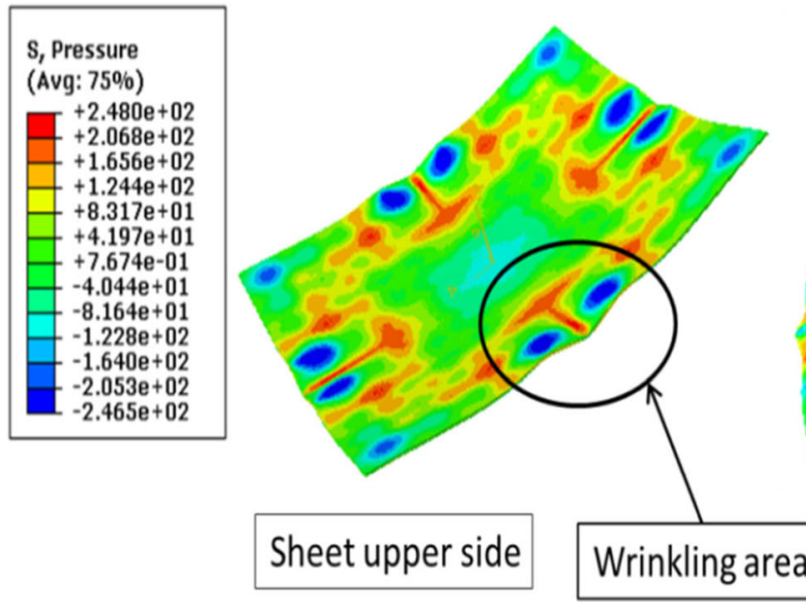

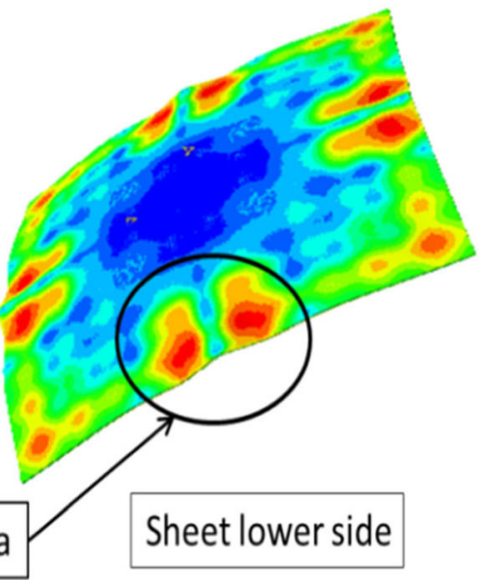

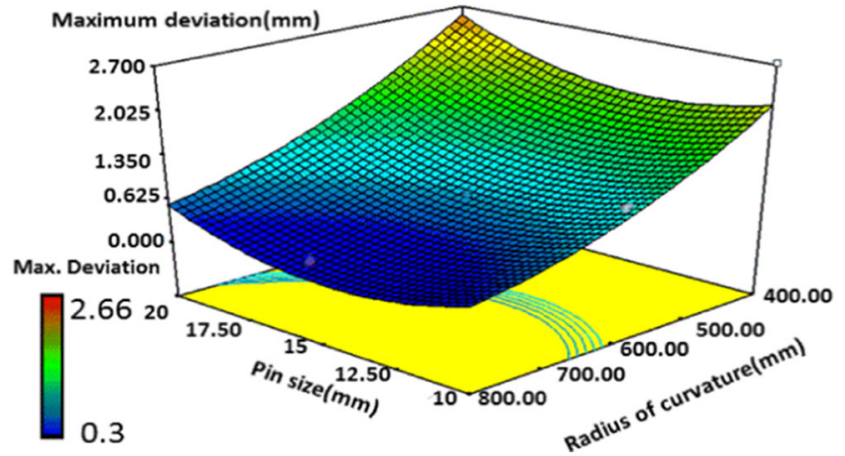

Fig. 11 Effect of pin size and radius of curvature on maximum shape deviation
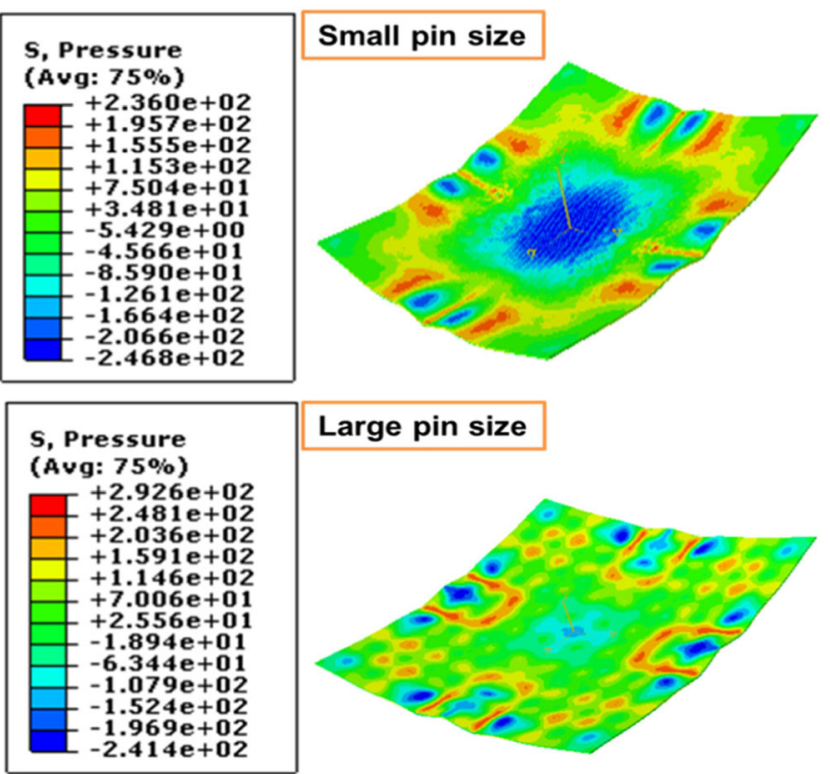

Fig. 12 Pressure distribution on the sheet when small pin size and large pin size are used (radius of curvature $=400 \mathrm{~mm}$ ) increases with a decrease in the radius of curvature. Using small pins (less $12.5 \mathrm{~mm}$ ) or large pins (more than $17.5 \mathrm{~mm}$ ) will increase the maximum deviation. Figure 12 shows the pressure distribution on the deformed sheet when small pins and large pins are used. Too small a pin (less than $12.5 \mathrm{~mm}$ ) will reduce the contact area which increases stresses. Excessive stresses will over-deform the sheet and increase the maximum deviation from the target. Too large a pin (more than $17.5 \mathrm{~mm}$ ) will increase the contact area, reducing stresses. Having insufficient stresses does not the required deformation and increases the deviation from the target. The minimum deviation from the target shape can be obtained when using a large radius of curvature $(800 \mathrm{~mm})$ and medium-size pins $(15 \mathrm{~mm})$.

\subsection{Thickness variation}

Figures 13 and 14 show the effect of the coefficient of friction, pin size and radius of curvature on thickness variation. As can be seen in Fig. 13, the higher the coefficient of friction, the larger the thickness variation. When the coefficient of friction increases, relative motion between the sheet and the cushion becomes difficult. This resists the material flow underneath the pins which leads to sheet thinning in the middle of the die and thickening at the sheet edges [21]. Additionally, a small pin size leads to an increase in the thickness variation. When small pins are adopted, the spacing between the pin tips decreases, which causes more resistance to the flow and deformation of the elastic cushion. This leads to non-uniform deformation of the sheet. The minimum thickness variation is obtained when using large pins and having zero friction. From Fig. 14, it can be seen that the thickness variation increased with increasing friction and curvature. The maximum 


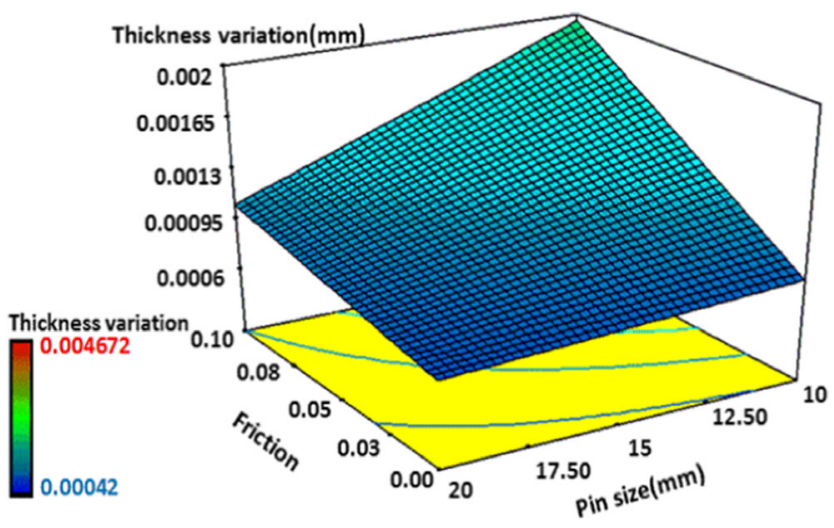

Fig. 13 Effect of coefficient of friction and pin size on thickness variation

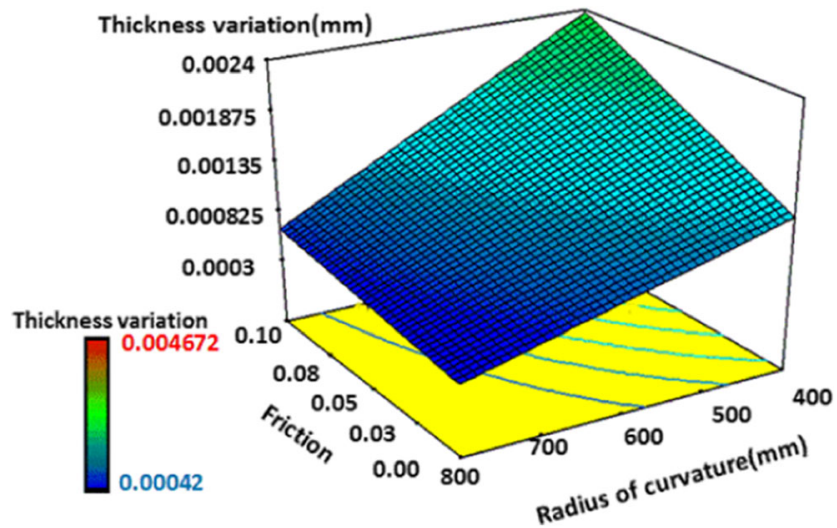

Fig. 14 Effect of coefficient of friction and radius of curvature on thickness variation

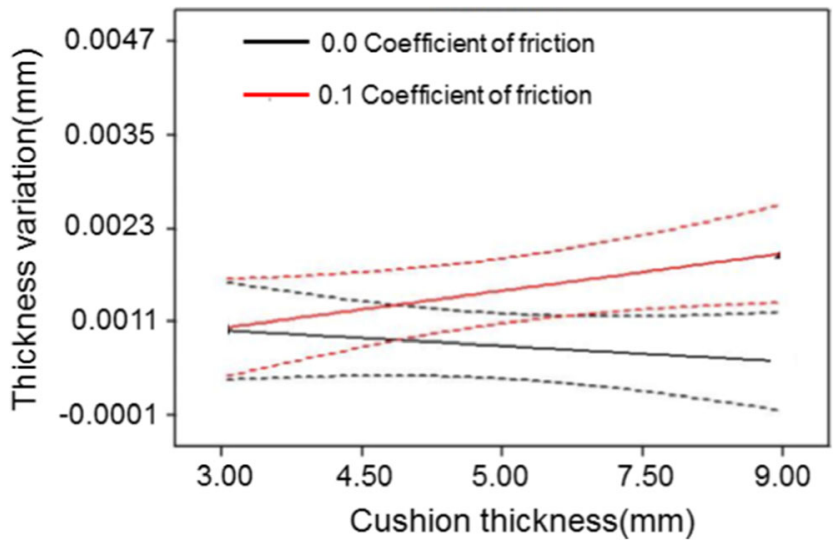

Fig. 15 Effect of interaction between cushion thickness and coefficient of friction on workpiece thickness variation

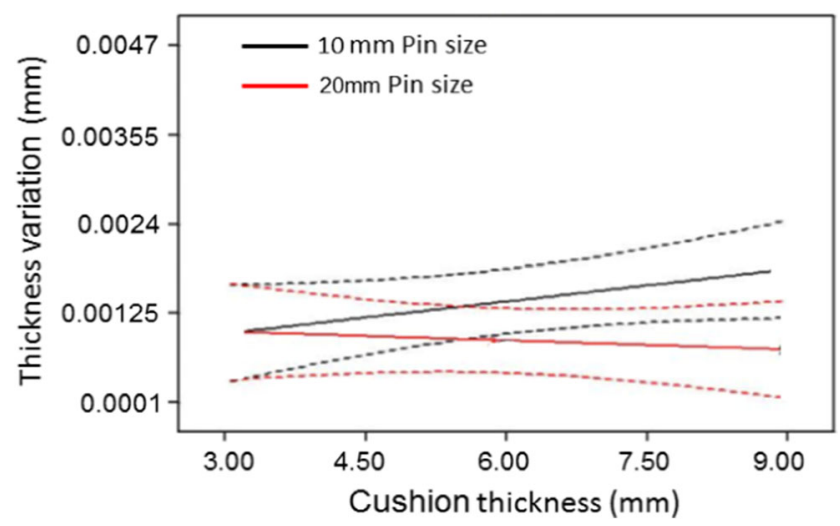

Fig. 16 Effect of interaction between cushion thickness and pin size on workpiece thickness variation

thickness variation occurs when the radius of the curvature is small $(400 \mathrm{~mm})$ and the friction is high $(0.1)$. When the curvature is small $(400 \mathrm{~mm})$, fewer pins will be in contact with the sheet at the beginning of deformation. As a result, stress concentration will occur, which leads to localised sheet thinning in the middle of sheet [22].

Figures 15 and 16 show the effect of interaction between elastic cushion thickness and coefficient of friction and between elastic cushion thickness and pin size on workpiece thickness variation. When there is no friction, the workpiece thickness variation decreases with an increase in elastic cushion thickness. When there is friction, the variation in the workpiece thickness increases with the elastic cushion thickness. A thick elastic cushion is expected to expand laterally when compressed. However, a high coefficient of friction will resist this expansion, which leads to non-uniform deformation. With large pins, the effect of cushion thickness on workpiece thickness variation becomes negligible. However, when small pins adopted, increasing the elastic cushion thickness will lead to an increase in the thickness variation [21]. This is because the gaps between the pins become smaller, which restrains the deformation of the elastic cushion. Thus, a combination of a thick elastic cushion and small pins causes the largest variation in workpiece thickness.

\section{Prediction of response factors}

An empirical model has been developed to predict wrinkling, maximum deviation from target and thickness variation using a general second-order polynomial equation (Eq. 5). This 
Table 5 Coefficient values corresponding to each response parameter

\begin{tabular}{llll}
\hline Coefficient & Wrinkling $(\mathrm{mm})$ & Maximum deviation $(\mathrm{mm})$ & Thickness variation $(\mathrm{mm})$ \\
\hline$k_{0}$ & 8.72134 & 8.6286 & $1.81246 \mathrm{E}-003$ \\
$k_{1}$ & 0.1224 & -0.097762 & $1.92104 \mathrm{E}-004$ \\
$k_{2}$ & -1.09204 & -6.59537 & 0.018333 \\
$k_{3}$ & -0.34898 & -0.41928 & $4.76361 \mathrm{E}-005$ \\
$k_{4}$ & -0.01809 & -0.011172 & $-3.44035 \mathrm{E}-006$ \\
$k_{5}$ & 0.075 & 0.00 & $2.25875 \mathrm{E}-003$ \\
$k_{6}$ & -0.00116667 & $-1.41667 \mathrm{E}-003$ & $-1.76792 \mathrm{E}-005$ \\
$k_{7}$ & -0.0000770833 & $9.16667 \mathrm{E}-005$ & $1.523276 \mathrm{E}-007$ \\
$k_{8}$ & 0.0363114175 & +0.11 & $-7.8275 \mathrm{E}-004$ \\
$k_{9}$ & 0.002125 & $3.625 \mathrm{E}-003$ & $-2.15938 \mathrm{E}-005$ \\
$k_{10}$ & -0.000055 & $-6.75 \mathrm{E}-005$ & $7.83125 \mathrm{E}-008$ \\
$k_{11}$ & -0.00405761 & $6.76955 \mathrm{E}-003$ & - \\
$k_{12}$ & -14.60741 & 18.37037 & - \\
$k_{13}$ & 0.013519 & 0.016437 & - \\
$k_{14}$ & 0.000012837 & $6.02315 \mathrm{E}-006$ & - \\
\hline
\end{tabular}

equation was constructed based on the process parameters, i.e. elastic cushion thickness, coefficient of friction, pin size and radius of curvature. Depending on the response parameter, each process parameter has related coefficients as listed in Table 5.

$$
\begin{aligned}
\operatorname{Response}(q)= & k_{0}+k_{1} A+k_{2} B+k_{3} C+k_{4} D \\
& +k_{5} A B+k_{6} A C+k_{7} A D+k_{8} B C \\
& +k_{9} B D+k_{10} C D+k_{11} A^{2}+k_{12} B^{2} \\
& +k_{13} C^{2}+k_{14} D^{2}
\end{aligned}
$$

where $q$ is the response parameter (i.e. wrinkling, maximum deviation from target or thickness variation), $A$ is the elastic cushion thickness, $B$ is the coefficient of friction, $C$ is the pin size, $D$ is the radius of curvature, and $k_{0}-k_{14}$ are the model coefficient values corresponding to each response parameter. Table 5 shows the values of $k_{0}-k_{14}$.

\section{Optimisation of process parameters}

Optimal working parameters were chosen to yield a spherical shape product that had almost no wrinkling and minimal shape deviation and thickness. The set of process parameters that can achieve this objective was numerically obtained as shown in Table 6. The optimal setting is $10-\mathrm{mm}$ pin size, 3-mm cushion thickness, 0.08 coefficient of friction and 800 radius of curvature. A single experiment was carried out using a MPF die with 10-mm pins (see Fig. 17a) to validate these results. The fabricated part is shown in Fig. 17b. The sheet was cut into two halves (see Fig. 17c). The profile of the deformed sheet was measured using a high-resolution 3D laser scanner. The data was then used to compare the formed shape with the target shape and to calculate the maximum deviation from target, as shown in Fig. 18. The thickness was measured using a high-resolution point-type digital micrometre at 17 points across the centre line of the deformed sheet as shown in Fig. 18. Table 7 shows that the predicted results agree well with the measurements.

Table 6 Optimum process parameters

\begin{tabular}{lllll}
\hline & $\begin{array}{l}\text { Cushion } \\
\text { thickness }(\mathrm{mm})\end{array}$ & Friction & $\begin{array}{l}\text { Pin size } \\
(\mathrm{mm})\end{array}$ & $\begin{array}{l}\text { Radius of } \\
\text { curvature }(\mathrm{mm})\end{array}$ \\
\hline Optimal condition & 3 & 0.08 & 10 & 800 \\
\hline
\end{tabular}


Fig. 17 a Multi-point forming die. b Fabricated part. c Part cut into two halves

Fig. 18 Comparison of formed shape with target shape

Table 7 Predicted and observed response parameters

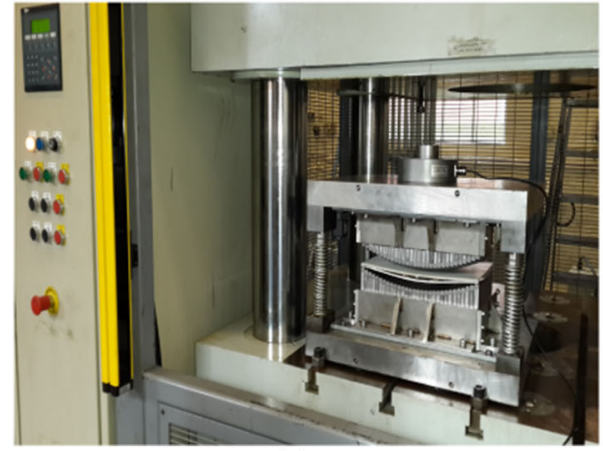

(a)

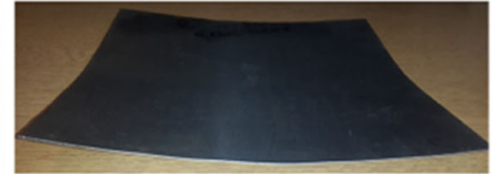

(b)

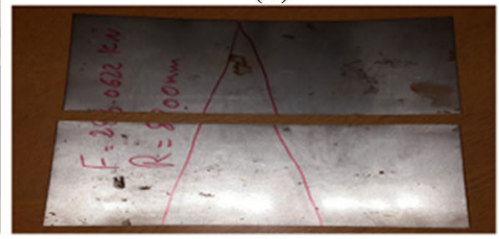

(c)

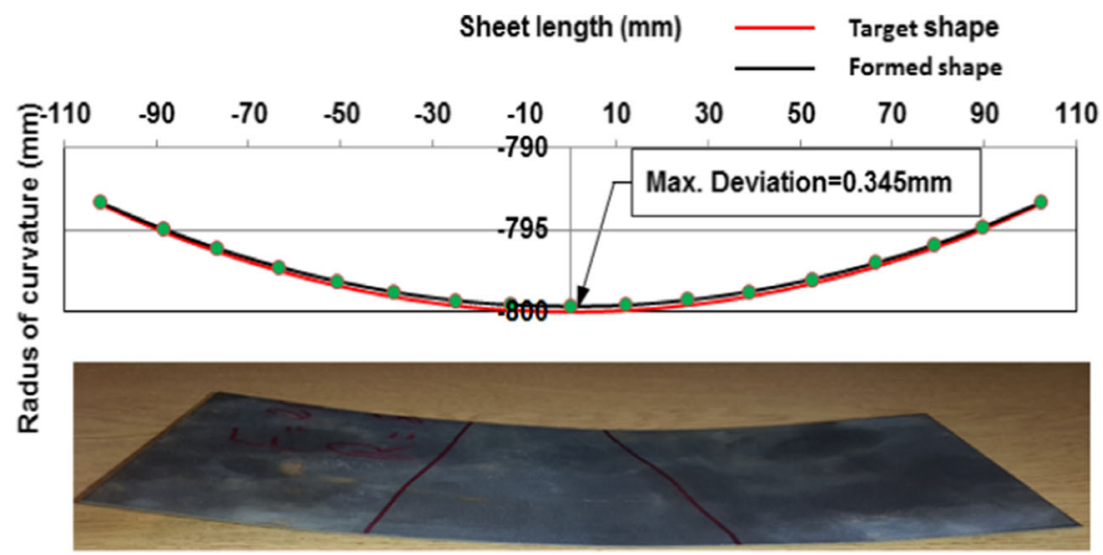

\begin{tabular}{llll}
\hline & Wrinkling $(\mathrm{mm})$ & Max. deviation $(\mathrm{mm})$ & Thickness variation $(\mathrm{mm})$ \\
\hline Predicted & $(2.01896 \mathrm{E}-007) \approx 0$ & 0.3111 & 0.000575 \\
Measured & 0.00 & 0.3450 & 0.000547 \\
\hline
\end{tabular}

\section{Conclusion}

In this investigation, finite element modelling was used to calculate the amount of deformation of a workpiece in MPF. The response surface method was employed to generate an experimental plan, and the ANOVA technique was adopted to identify significant process parameters. This study demonstrated the following:

1. The pin size and radius of curvature have a significant effect on all response parameters, i.e. wrinkling, maximum deviation from target shape and thickness variation, while the coefficient of friction only has a significant effect on the thickness variation.
2. For each of the response parameters, there were significant parameter interactions; a mathematical model can be obtained accurately to describe the influence of the process parameters.

3. As the workpiece radius of curvature decreased, wrinkling, maximum shape deviation and thickness variation increased. Both large and small pins lead to increased wrinkling and maximum shape deviation while using large pins reduces thickness variation. A high coefficient of friction leads to increased thickness variation.

4. A doubly curved sheet could be produced with no wrinkling, accurate dimensions and high thickness uniformity. 
Acknowledgements This work was part of the "Automated Manufacturing Process Integrated with Intelligent Tooling Systems (AUTOMAN)" project supported by the Engineering and Physical Sciences Research Council and Innovate UK (Grant Reference EP/ L505225/1).

Open Access This article is distributed under the terms of the Creative Commons Attribution 4.0 International License (http:// creativecommons.org/licenses/by/4.0/), which permits unrestricted use, distribution, and reproduction in any medium, provided you give appropriate credit to the original author(s) and the source, provide a link to the Creative Commons license, and indicate if changes were made.

\section{References}

1. Walczyk DF, Hardt DE (1998) Design and analysis of reconfigurable discrete dies for sheet metal forming. J Manuf Syst 17(6):436-454

2. Qian Z, Li M, Tan F (2007) The analyse on the process of multi-point forming for dish head. J Mater Process Technol 187:471-475

3. Cai Z-Y, Wang S-H, Li M-Z (2008) Numerical investigation of multi-point forming process for sheet metal: wrinkling, dimpling and springback. Int J Adv Manuf Technol 37(9-10):927936

4. Paunoiu V, Cekan P, Gavan E, Nicoara D (2008) Numerical simulations in reconfigurable multipoint forming. Int J Mater Form 1(1): 181-184

5. Paunoiu V, Teodor V, Maier C, Baroiu N, Bercu G (2011) Study of the tool geometry in reconfigurable multipoint forming. The Annals of Dunărea de Jos University of Galați, Fascicle V, Technologies In Machine Building, ISSN, p 1221-4566

6. Kadhim AJ, Abbas, MI (2013) Influence of die elements shapes on process parameters in multi-point sheet metal forming process. 3rd International conference on management, economics and social sciences (ICMESS'2013), Kuala Lumpur (Malaysia), 8-9 January 2013

7. Abebe M, Lee K, Kang BS (2016) Surrogate-based multi-point forming process optimization for dimpling and wrinkling reduction. Int J Adv Manuf Technol 85(1-4):391-403

8. Abebe M, Lee K, Kang B-S (2015) Surrogate-based multi-point forming process optimization for dimpling and wrinkling reduction.
The International Journal of Advanced Manufacturing Technology: p. 1-13

9. Essa K, Hartley P (2010) Optimization of conventional spinning process parameters by means of numerical simulation and statistical analysis. Proc Inst Mech Eng B J Eng Manuf 224(11):1691-1705

10. Read NW, Essa W, Attallah K, Moataz M (2015) Selective laser melting of AlSi10Mg alloy: process optimisation and mechanical properties development. Mater Des 65:417-424

11. Hosford WF, Caddell RM (2011) Metal forming: mechanics and metallurgy. Cambridge University Press

12. Cai ZY, Wang SH, Xu XD, Li MZ (2009) Numerical simulation for the multi-point stretch forming process of sheet metal. J Mater Process Technol 209(1):396-407

13. Quan G-Z, Ku T-W, Kang B-S (2011) Improvement of formability for multi-point bending process of AZ31B sheet material using elastic cushion. Int J Precis Eng Manuf 12(6): 1023-1030

14. Seo Y-H, Kang B-S, Kim J (2012) Study on relationship between design parameters and formability in flexible stretch forming process. Int J Precis Eng Manuf 13(10):1797-1804

15. Wang S, Cai Z, Li M (2010) Numerical investigation of the influence of punch element in multi-point stretch forming process. Int J Adv Manuf Technol 49(5-8):475-483

16. Documentation A (2013) Getting started with Abaqus: interactive edition. http://abaqusdoc.ucalgary.ca/v6.9/books/gsa/default.htm.

17. Abdulkareem JK, Mostafa IA, (2014) International Journal of Mining, Metallurgy \& Mechanical Engineering (IJMMME'2014), ISSN 2(1):2320-4060

18. Hassanin H, Modica F, El-Sayed MA, Liu J, Essa K (2016) Manufacturing of Ti-6Al-4V micro-implantable parts using hybrid selective laser melting and micro-electrical discharge machining. Adv Eng Mater 18(9):1544-1549

19. Carter LN, Essa K, Attallah MM (2015) Optimisation of selective laser melting for a high temperature Ni-superalloy. Rapid Prototyp J 21(4):423-432

20. Lind DA, Marchal WG, Wathen SA (2005) Statistical techniques in business and economics. 12th Ed. Boston: McGraw Hill Irwin

21. Liu Y, Li M, Ju F, (2016) Research on the process of flexible blank holder in multi-point forming for spherical surface parts. Int J Adv Manuf Technol, p.1-8

22. Lemes S, Zaimovic-Uzunovic N (2008) Using buckling analysis to predict wrinkling in incremental sheet metal forming. STROJNISKI VESTNIK 54(2):115 